\title{
Hubungan Pengetahuan Ibu Hamil Tentang Program 1000 Hari Pertama Kehidupan Dengan Stimulasi Anak Dalam Kandungan
}

\author{
Tri Sunarsih ${ }^{1 *}$, Diah Amanta Karunia Dewi ${ }^{1}$, Anjeli Ratih Syamlingga Putri ${ }^{2}$ \\ ${ }^{1}$ Universitas Jenderal Achmad Yani, Yogyakarta \\ ${ }^{2}$ Universitas 'Aisyiyah, Yogyakarta \\ *Corresponding author : are_she79@yahoo.com
}

Info Artikel : Diterima 25 April 2019 ; Disetujui 10 November 2020 ; Publikasi 1 Februari 2020

\begin{abstract}
ABSTRAK
Latar Belakang: Hari pertama kehidupan yaitu masa selama 270 hari dalam kandungan ditambah 730 hari pasca lahir. Periode 1000 hari pertama ini juga disebut periode emas (golden period), pada masa janin sampai anak usia dua tahun terjadi proses tumbuh kembang yang sangat cepat dan tidak terjadi pada kelompok usia lain. Namun sebagian besar ibu hamil belum mengetahui tentang program 1000 HPK. Tujuan penelitian yaitu untuk mengetahui Hubungan Pengetahuan Ibu Hamil tentang Program 1000 Hari Pertama Kehidupan Dengan Stimulasi Anak Dalam Kandungan.

Metode: Jenis penelitian yang digunakan adalah penelitian kuantitatif jenis explanatory study. Pelaksanaan penelitian menggunakan metode survei dengan pendekatan cross sectional. Teknik sampling menggunakan purposive sampling. Analisis data yang digunakan uji statistic chi square.

Hasil: Hasilnya terdapat hubungan yang signifikan antara pengetahuan ibu hamil tentang program 1000 HPK dengan stimulasi anak dalam kandungan, dengan nilai korelasi sebesar 0.232 yang termasuk kedalam kategori rendah (0.20-0.399). Simpulan: Hendaknya untuk orangtua dengan semaksimal mungkin untuk memberikan pendidikan anak sewaktu dalam kandungan. Hendaknya petugas KIA memberikan penyuluhan tentang pendidikan anak dalam kandungan.
\end{abstract}

Kata kunci: Pengetahuan, Program 1000 HPK, Stimulasi Anak Dalam Kandungan

\section{ABSTRACT}

Title: Relationship Of The Knowledge Of Pregnant Women About The First 1000 Day Life Program With Children Stimulation In Content

Background: The first day of life is 270 days in the womb plus 730 days after birth. The first 1000 days period is also called the golden period, during the fetus until the two-year-old child develops very fast growth and does not occur in other age groups. But most pregnant women do not know about the 1000 HPK program. The aim of the study was to find out the Relationship between Knowledge of Pregnant Women about the First 1000 Days of Life Program with Stimulation of Children in the Contents.

Methods: The type of research used is an explanatory study quantitative research. The study uses a survey method with a cross sectional approach. The sampling technique uses purposive sampling.

Data analysis used chi square statistical test.

Results: There is a significant relationship between the knowledge of pregnant women about the 1000 HPK program and stimulation of the child in the womb, with a correlation value of 0.232 which falls into the low category (0.20-0.399). Conclusion: Should for parents as much as possible to provide education for children while in the womb. KIA officers should provide counseling about the education of children in the womb.

Keywords: Knowledge, 1000 HPK Program, Stimulation of Children in Contents 


\section{PENDAHULUAN}

Angka Kematian Ibu (AKI) di negara-negara Asia Tenggara seperti Malaysia (29/100.000 KH), Thailand (48/100.000 KH), Vietnam $(59 / 100.000$ $\mathrm{KH}$ ), serta Singapore (3/100.000 KH) (WHO, 2013). Angka Kematian Ibu (AKI) di Indonesia tahun 2015 tergolong masih cukup tinggi dibandingkan negara-negara lain yaitu mencapai 305 per 100.000 kelahiran hidup, jika dibandingkan dengan AKI tahun 2014 sebesar 359/100.000 kelahiran hidup, jauh menurun jika dilihat dari jumlahnya dan masih jauh dari target Sustainable Development Goals (SDGs) $2030 \quad$ (70/100.000 kelahiran hidup). Masih memerlukan kerja keras dari semua komponen untuk mencapai target tersebut.

Angka Kematian Ibu (AKI) di Daerah Istimewa Yogyakarta tahun $2014 \quad(40$ ibu $)$ mengalami penurunan dibandingkan dengan tahun 2013 (46 ibu) sedangkan pada tahun 2015 jumlah kematian ibu di setiap kabupaten adalah kabupaten Kulon Progo sebanyak (2 ibu), Bantul (11 ibu), Gunung Kidul (7 ibu), Sleman (4 ibu), Kota Yogyakarta (2 ibu). Jumlah kematian juga terjadi pada kematian neonatus, bayi dan balita. Profil kesehatan DIY tahun 2015 menyebutkan bahwa Angka Kematian Balita (AKBA) di DIY adalah 9,8 per 1000 kelahiran hidup dan menunjukkan bahwa DIY telah memenuhi target Pemerintah Indonesia (32 per 1000 kelahiran hidup). Jumlah angka kematian bayi (AKB) di DIY pada tahun 2014 menunjukkan 274 bayi lahir ${ }^{1}$.

Pemeriksaan kehamilan sangat penting dilakukan oleh semua ibu hamil untuk mengetahui pertumbuhan janin dan kesehatan ibu. Hampir seluruh ibu hamil di Indonesia $(95,75 \%)$ sudah melakukan pemeriksaan kehamilan (K1) dan frekuensi kehamilan minimal 4 kali selama masa kehamilannya adalah 87,48 persen. Cakupan pelayanan kesehatan ibu hamil K4 pada tahun 2015 telah memenuhi target Rencana Strategis (Renstra) Kementerian Kesehatan sebesar $72 \%{ }^{2}$.

Dari data yang diperoleh cakupan K1 dan K4 tertinggi adalah daerah Sleman, dari grafik pencapaian per Puskesmas untuk K1 telah mencapai $100 \%$ disemua puskesmas, cakupan K4 telah mencapai diatas 95\% sebanyak 23 Puskesmas sedangkan yang belum memenuhi $95 \%$ sebanyak dua Puskesmas yaitu Mlati II dan Depok I masingmasing sebesar $93,5 \%$ dan $91,5 \%{ }^{3}$.

Pelayanan asuhan antenatal perlu dilaksanakan secara terpadu maupun terintegrasi pada 1000 hari pertama kehidupan (HPK). 1000 hari pertama kehidupan yaitu masa selama 270 hari ( 9 bulan) dalam kandungan ditambah 730 hari (2 tahun pertama) pasca lahir. Periode 1000 hari pertama ini sering disebut window of opportunities atau sering juga disebut periode emas (golden period), pada masa janin sampai anak usia dua tahun terjadi proses tumbuh kembang yang sangat cepat dan tidak terjadi pada kelompok usia lain.Gerakan 1000 hari pertama kehidupan antara lain diarahkan untuk mencapai target yaitu menurunkan proporsi anak balita stunting sebesar $40 \%$, menurunkan proporsi anak balita yangmenderita kurus (wasting) kurang dari 5\%, menurunkan proporsi bayi lahir dengan berat badan rendah sebesar $30 \%$, tidak ada kenaikan proporsi anak yang mengalami gizi lebih, menurunkan proporsi wanita usia subur yang menderitaanemia sebanyak $50 \%$, dan meningkatkan prosentase ibu yang memberikan ASI eksklusif selama 6 bulan palingkurang $50 \%$.

Istilah 1000 hari pertama kehidupan atau the first thousand days mulai diperkenalkan pada 2010 sejak dicanangkan Gerakan Scalling-up Nutrition $(S U N)$ di tingkat global. Hal ini merupakan upaya sistematis yang melibatkan berbagai pemangku kepentingan khususnya pemerintah, dunia usaha dan masyarakat untuk memberikan perhatian khusus kepada ibu hamil sampai anak usia 2 tahun. Keadaan yang buruk selama kehamilan,seperti difisiensi nutrisi selama kehamilan, stress maternal,olahraga yang tidak cukup, dan perawatan prenatal yang tidak memadai, dapat menyebabkan perkembangan janin yang tidak optimal.Perkembangan janin yang buruk merupakan resiko kesehatan pada kehidupan selanjutnya ${ }^{4}$.

Global sun movement mempunyai tujuan untuk menurunkan masalah gizi, dengan fokus pada 1000 HPK yaitu pada ibu hamil, ibu menyusui dan anak usia 0-23 bulan. Gerakan Scalling-up Nutrition (SUN) movement di Indonesia dikenal dengan gerakan Nasional Percepatan Perbaikan Gizi dalam Rangka Seribu Hari Pertama Kehidupan (HPK). Program 1000 HPK ini terdiri dari program spesifik dan program sensitif. Program spesifik dilakukan secara langsung terhadap kelompok sasaran 1000 HPK oleh sektor kesehatan yaitu ibu hamil, bayi 0-6 bulan dan bayi 7-23 bulan sedangkan program sensitif merupakan kegiatan yang dilakukan lintas sektor dengan sasaran masyarakat umum yang dampaknya sensitif keselamatan proses pertumbuhan dan perkembangan $1000 \mathrm{HPK}$.

Kekurangan gizi pada masa janin dan usia 2 tahun pertama kehidupan berpengaruh sangat penting terhadap resiko terjadi berbagai penyakit tidak menular yang kronis pada usia dewasa (Endang L. Achadi dkk, 2012). Kartono Kartini (1992) dalam Yani (2009) menulis tentangperan seorang wanita yang berkaitan dengan kedudukannya dalam keluarga wanita sangat berperan penting dalam memelihara kesehatan keluarga, menyiapkan makanan bergizi setiap hari dan bertanggung jawab terhadap sanitasi rumah tangga juga menciptakan pola hidup sehat jasmani, rohani dan sosial terutama pada masa 1000 HPK. Bagi wanita yang tengah mempersiapkan kehamilan, penting bagi mereka untuk mengetahui tentang gizi seimbang mulai dari awal kehamilan 
sampai anak usia dua tahun agar bayi lahir sehat serta terhindar dari berbagai masalah gizi.

\section{METODE}

Metode kegiatan KKN-PPM ini adalah metode workshop dalam bentuk pelatihan dan pendampingan secara intensif sampai menghasilkan produk berupa buku panduan pengkajian kesehatan ibu dan anak. Dilakukan dua kegiatan yaitu: Pertama, pembekalan kepada masyarakat desa Ambarketawang melalui pembentukan manajer komunitas yang terdiri atas unsur kader kesehatan dan tokoh masyarakat. Materi pembekalan yaitu cara mengoordinasikan dan menggerakkan masyarakatnya/komunitas dan konsep pemberdayaan masyarakat, sehingga bersama-sama masyarakatnya mampu mengidentifikasi, merencanakan, melaksanakan, memonitor, dan mengevaluasi program kesehatan terutama berbagai program KIA. Kedua, pendampingan praktik pemberdayaan masyarakat yang dilakukan manajer komunitas pada keluarga dalam bidang KIA. Selain itu membentuk kegiatan yang mendukung KIA seperti pembentukan babyfood cafe, kelompok remaja sehat, OCOC (one cadre one client) untuk ibu hamil.

\section{HASIL DAN PEMBAHASAN}

Pada penelitian ini diketahui bahwa sebagian besar responden berumur 20 - 35 tahun, yaitu sebanyak 60 responden $(75,0 \%)$, dengan pendidikan terakhir sampai tingkat SMA sebanyak 40 responden $(50,0 \%)$, dengan status pekerjaan ibu rumah tangga/IRT sebanyak 38 responden $(47,5 \%)$, ibu dengan jumlah anak 1 anak sebanyak 45 responden $(56,3 \%)$ dan dengan status kehamilan ke 2 sebanyak 42 responden $(52,5 \%)$.

Hasil penelitian ini juga dapat diketahui bahwa, sebagian besar responden merupakan ibu dengan tingkat pengetahuan ibu hamil tentang program 1000 HPK kategori cukup, yaitu sebanyak 36 responden (45,0\%). Selain itu, pada penelitian ini diketahui bahwa sebagian besar responden merupakan ibu hamil yang memberikan stimulasi pendidikan anak dalam kandungan dalam kategori baik, yaitu sebanyak 44 responden $(55,0 \%)$.

Dari hasil perhitungan diperoleh nilai signifikansi sebesar $0.026<\alpha(0.05)$ maka hipotesis kerja h1 diterima. Artinya terdapat hubungan yang signifikan antara pengetahuan ibu hamil tentang program 1000 HPK dengan stimulasi anak dalam kandungan. Hubungan ini ditunjukan dengan nilai korelasi sebesar 0.232 yang termasuk kedalam kategori rendah $(0.20$ 0.399).

Hasil penelitian yang dilakukan di Puskesmas Mlati II Sleman, Daerah Istimewa Yogyakarta, dengan jumlah responden 80 responden. Berdasarkan hasil penelitian terdapat hubungan pengetahuan ibu hamil tentang program 1000 HPK dengan stimulasi anak dalam kandungan namun hubungan itu rendah. Pemahaman ibu hamil tentang program 1000 HPK meliputi pengertian, kegiatan intervensi spesifik, kegiatan intervensi sensitif dan nutrisi. Pengetahuan seseorang tentang suatu objek mengandung dua aspek, yaitu aspek positif dan negatif. Pengetahuan ibu hamil tentang pengertian program 1000 Hari Pertama Kehidupan (HPK) cukup. Ketika ibu ditanya ibu sudah mengerti mengenai pengertian 1000 HPK bahwa kepanjangan dari 1000 HPK adalah 1000 Hari Pertama Kehidupan. Namun ibu belum mengerti mengenai item pernyataan bahwa 1000 HPK merupakan suatu awal kehidupan mulai dari masa kehamilan hingga anak berusia 2 tahun.

Berdasarkan penelitian yang dilakukan oleh Firmansyah tahun 2016 yang menyatakan bahwa 1000 hari pertama kehidupan seorang anak semakin diakui sebagai kerangka waktu penting untuk kesehatan hingga menjadi dewasa diimana nutrisi memainkan peran penting untuk status kesehatan kehidupan seseorang, sehingga dengan meningkatkan pengetahuan ibu hamil dapat emningkatkan kesehatan dan kesejahteraan bagi ubu dan bayinya (Firmansyah et al., 2016)

Pengetahuan ibu hamil tentang program 1000 HPK masih kurang. Ketika ibu ditanya ibu belum mengerti mengenai item pernyataan bahwa mengonsumsi suplemen zat besi secara rutin saat hamil dapat mencegah penyakit anemia. Namun ibu sudah mengerti mengenai program 1000 HPK bahwa pendidikan gizi pada remaja merupakan salah satu kegiatan intervensi sensitif pada program 1000 HPK .

Kedua aspek ini yang akan menentukan sikap seseorang. Semakin banyak aspek yang diketahui, maka akan menimbulkan sikap yang semakin positif terhadap suatu objek menurut WHO (World Health Organization) dalam Wawan (2010). Selain itu, pendekatan multisektoral kepada perempuan juga dibutuhkan untuk memberikan saran tentang perkembangan dan bagaimana stimulan anak agar anak didalam kandungan dapat berkembang lebih baik (Gladstone et al., 2018).

Ketika ditanya, ibu hamil sering melakukan dzikir. Ibu paham pentingnya sentuhan kasih sayang dan komunikasi saat anak masih dalam kandungan, karena dapat menstimulasi rasa kasih sayang dan kedamaian terhadap calon bayi, sehingga akan tumbuh lebih sehat dan nyaman dalam rahim. Hal ini diperkuat dengan hasil penelitian Kusrinah (2013) bahwa ibu yang sering membaca Al-Qur'an dapat merangsang otak anak dan meningkatkan intelegensinya ${ }^{7}$. Hal ini juga diperkuat dengan hasil penelitian dari Amalia (2011) bahwa dengan memberikan sentuhan pada janin, ia akan semakin mengenali siapa ibunya ${ }^{8}$. Kelak akan mampu memperbaiki emosional alamiah dari janin itu 
sendiri dan dapat mempengaruhi kecerdasan bayi. Sejalan dengan hasil penelitian dari Dr. Masaru Emoto (2014) yang menunjukkan kekuatan air, dimana kata-kata dapat mempengaruhi kualitas air ${ }^{9}$. Jika kata-kata positif yang diberikan, terbentuklah kristal air heksagonal yang indah merekah laksana bunga yang sedang mekar. Sebaliknya, jika katakata negatif yang diberikan, akan menghasilkan pecahan kristal dengan ukuran yang tidak seimbang. Bentuk kristalnya jelek dan tidak beraturan.

Ibu juga memperdengarkan musik jika sedang beristirahat. Hal ini sejalan dengan hasil penelitian Gunes dan Gunes (2012), pada zaman dahulu ibu hamil menyanyikan lagu pengantar tidur terhadap anak dalam rahim yang sangat efektif sebagai sarana komunikasi dan pendidikan ${ }^{10}$. Sesuai dengan penelitian Zakiyah dan Hasan (2014) menjelaskan beberapa metode yang dapat digunakan untuk mendidik anak dalam kandungan yaitu: metode do'a, ibadah, membaca dan menghafal, dzikir, metode dialog.

Secara fisik ibu juga menjaga kesehatan dan menjaga pola makannya dengan makan makanan yang bergizi. Pengetahuan ibu hamil tentang nutrisi program 1000 HPK sudah baik. Ibu sudah mengerti mengenai nutrisi program 1000 HPK bahwa zat besi juga dapat diperoleh melalui makanan yang berupa sayuran hijau seperti bayam, brokoli dan kacangkacangan. Sementara itu, apabila ibu hamil yang mempunyai pola diet yang tidak sehat (asupan lemak tinggi) pada saat kehamilannya dapat meningkatkan perubahan perkembangan paru-paru janin dan peningkatan risiko gangguan pernapasan ${ }^{11}$

Pada penelitian ini untuk nutrisi, ibu belum mengerti mengenai konsumsi kalsium pada ibu hamil diperlukan untuk pembentukan tulang dan gigi serta persendian janin. Seperti penelitian dari Zakiyah dan Hasan (2014) salah satu cara mendidik anak dalam kandungan adalah dengan cara ibu menjaga kesehatannya dengan nutrisi yang cukup.

Selain itu, berdasrkan hasil penelitian Sharma tahun 2017 yang merekomendasikan bahwa untuk meningkatkan stimulasi perkembangan bayi dalam kandungan juga diperlukan komunitas global pendonor, dokter, peneliti, pembuat kebijakan dan amanjer program untuk mengadvokasi maslah kesehatan gizi, pendidikan dan perlindungan sosial serta pengetahuan ibu hamil untuk meningkatkan kesehatan bagi ibu hamil dan stimulasi bayi dalam kandungannya ${ }^{12}$.

Kualitas bayi dari ibu merupakan aspek penting dari lingkungan pengasuhan awal yang menetapkan landasan bagi perkembangan anak. Stimuasi juga dikaitkan dengan perkembangan sosial emosional dan kognitif, serta self efficacy dari ibu ${ }^{13}$ (Edwards, Thullen, Henson, Lee, \& Hans, 2015).

Berdasarkan karakteristik responden, hasil penelitian ini sangat dipengaruhi oleh pendidikan ibu yang sebagian besar responden memiliki jenjang pendidikan akhir hingga SMA (50,0\%). Sejalan dengan penelitian Ulfa (2006), bahwa tingkat pendidikan formal ibu berbanding lurus dengan tingkat pengetahuannya, sebab semakin tinggi tingkat pendidikan formal ibu akan sejalan dengan peningkatan wawasan berfikirnya yang akan menyebabkan lebih banyak informasi yang diserap. Hal ini juga diperkuat dengan penelitian Sukesih (2012) yang menyebutkan bahwa ibu hamil yang berpendidikan tinggi berpeluang 8.1 kali memiliki pengetahuan lebih baik mengenai tanda bahaya dalam kehamilan dibandingkan dengan ibu hamil yang berpendidikan rendah. Sejalan dengan hasil penelitian Mbada et al (2014), ibu hamil yang memiliki pendidikan tinggi akan cenderung mempunyai pengetahuan yang baik dan sikap positif terkait latihan fisik yang dilakukan selama kehamilan. Rahayu et al (2012) juga mengatakan bahwa tingkat pendidikan yang tinggi bekaitan dengan pengetahuan yang tinggi. Semakin tinggi tingkat pendidikan seseorang maka semakin mudah orang tersebut untuk menerima informasi termasuk informasi kesehatan. Tinggi rendahnya pendidikan ibu berkaitan dengan tingkat perawatan kesehatan, pendapatan, pekerjaan, dan makanan.

Perkerjaan ibu sebagian besar adalah ibu rumah tangga (47,5\%). Hal tersebut jelas mempengaruhi pengetahuan ibu tentang pendidikan dalam kandungan, dikarena aktifitas ibu sangat terbatas dan lebih sering dirumah sehingga para ibu kurang memperoleh informasi yang lengkap mengenai program 1000 HPK. Perilaku yang muncul diawali dengan pengalaman seseorang yang akan melahirkan suatu bentuk persepsi sehingga menimbulkan motivasi, niat untuk bertindak .

Faktor umur menunjukkan bahwa sebagian besar resonden berumur antara 20-35 tahun (32,5\%) dan masih dalam kategori usia reproduksi sehat. Pada usia tersebut responden akan lebih mudah memahami dan mengerti tentang informasi atau pengetahuan baru mengenai program 1000 HPK. Usia berkaitan erat kematangan berfikir seseorang yang berpengaruh dalam pengambilan suatu keputusan untuk menentukan jenis aktifitas yang paling tepat. Seseorang yang masih muda memiliki produktifitas yang lebih baik jika dibandingkan dengan seseorang yang berusia lebih tua, hal ini dikarenakan masih baiknya kesehatan dan kondisi fisik pada orang yang berusia lebih ${ }^{14}$. 
Tabel 1. Distribusi Frekuensi Karakteristik Responden

\begin{tabular}{|c|c|c|}
\hline Karakteristik Responden & $\mathrm{n}$ & $\%$ \\
\hline Umur & & \\
\hline$<20$ Tahun & 10 & 12.5 \\
\hline 20 - 35 Tahun & 60 & 75.0 \\
\hline > 35 Tahun & 10 & 12.5 \\
\hline
\end{tabular}

Pendidikan

$\begin{array}{ccc}\text { SD } & 8 & 10.0 \\ \text { SMP } & 18 & 22.5 \\ \text { SMA } & 40 & 50.0 \\ \text { PerguruanTinggi } & 14 & 17.5\end{array}$

Pekerjaan

Ibu Rumah Tangga (IRT) $\quad 38 \quad 47.5$

Karyawan Swasta $\quad 14 \quad 17.5$

Wiraswasta $\quad 20 \quad 25.0$

PNS $\quad 8 \quad 10.0$

Jumlah Anak

$\begin{array}{ccc}\text { Belum Ada Anak } & 22 & 27.5 \\ 1 \text { Anak } & 45 & 56.3 \\ 2 \text { Anak } & 10 & 12.5 \\ 3 \text { Anak } & 3 & 3.8\end{array}$

Kehamilan Ke

\begin{tabular}{ccc} 
Pertama & 20 & 25.0 \\
Kedua & 42 & 52.5 \\
Ketiga & 14 & 17.5 \\
Keempat & 4 & 5.0 \\
Jumlah & 80 & 100 \\
\hline
\end{tabular}

Tabel 2. Distribusi Frekuensi Berdasarkan Tingkat Pengetahuan Ibu Hamil Tentang Program 1000 HPK

\begin{tabular}{ccc}
\hline Pengetahuan Ibu Hamil Tentang Program 1000 HPK & $\mathrm{n}$ & $\%$ \\
\hline Baik & 16 & 20.0 \\
Cukup & 36 & 45.0 \\
Kurang & 28 & 35.0 \\
\hline Jumlah & 80 & 100 \\
\hline
\end{tabular}

Tabel 3. Distribusi Frekuensi Berdasarkan Stimulasi anak dalam kandungan

\begin{tabular}{ccc}
\hline Stimulasi anak dalam kandungan & $\mathrm{N}$ & $\%$ \\
\hline Baik & 44 & 55,0 \\
Cukup baik & 28 & 35,0 \\
Kurang baik & 8 & 10,0 \\
Tidak baik & 0 & 0,0 \\
\hline Jumlah & 80 & 100 \\
\hline
\end{tabular}

Tabel 4. Uji statistik hubungan pengetahuan ibu hamil tentang pendidikan anak dalam kandungan dengan stimulasi anak dalam kandungan

\begin{tabular}{rrlrr}
\hline & & Pengetahuan & \multicolumn{2}{c}{ Stimulasi } \\
\hline Kendall's tau_b & Pengetahuan & Correlation Coefficient & 1.000 & $.232^{* *}$ \\
& & Sig. (2-tailed) &. & .026 \\
& & $\mathrm{~N}$ & 80 & 80 \\
& Stimulasi & Correlation Coefficient & $.232^{* *}$ & 1.000 \\
& & Sig. (2-tailed) & .026 & 80 \\
& $\mathrm{~N}$ & 80 &. \\
& & &
\end{tabular}




\begin{tabular}{|c|c|c|c|c|}
\hline & & & Pengetahuan & Stimulasi \\
\hline \multirow{6}{*}{ Kendall's tau_b } & \multirow[t]{3}{*}{ Pengetahuan } & Correlation Coefficient & 1.000 & $.232^{* *}$ \\
\hline & & Sig. (2-tailed) & . & .026 \\
\hline & & $\mathrm{N}$ & 80 & 80 \\
\hline & \multirow[t]{3}{*}{ Stimulasi } & Correlation Coefficient & $.232^{* *}$ & 1.000 \\
\hline & & Sig. (2-tailed) & .026 & \\
\hline & & $\mathrm{N}$ & 80 & 80 \\
\hline Correlation is & ignificant at th & .01 level (2-tailed). & & \\
\hline
\end{tabular}

\section{SIMPULAN}

Pengetahuan ibu hamil tentang 1000 HPK di Puskesmas Mlati II Sleman Yogyakarta dalam kategori baik. Pemahaman ibu hamil tentang program 1000 hari pertama kehidupan meliputi pengertian, kegiatan intervensi spesifik, kegiatan intervensi sensitif dan nutrisi. Stimulasi anak dalam kandungan Di Puskesmas Mlati II Sleman Yogyakarta dalam kategori baik. Stimulasi yang diberikan dengan sering melakukan dzikir, membaca Al-Qur'an, dengan memberikan sentuhan pada janin, memperdengarkan musik. Semakin banyak aspek pengetahuan yang diketahui, maka akan menimbulkan sikap yang semakin positif terhadap suatu objek menurut WHO (World Health Organization) dalam Wawan (2010). Selain itu, pendekatan multisektoral kepada perempuan juga dibutuhkan untuk memberikan saran tentang perkembangan dan bagaimana stimulan anak agar anak didalam kandungan dapat berkembang lebih baik.

\section{DAFTAR PUSTAKA}

1. Dinas Kesehatan Kota Yogyakarta. Profil Kesehatan Kota Yogyakarta Tahun 2015. Yogyakarta : Dinas Kesehatan Kota Yogyakarta; 2014

2. Kemenkes. Rencana Strategis Kementerian Kesehatan Tahun 2015-2019. Jakarta: Kementerian Kesehatan RI; 2015.

3. Dinas Kesehatan. Profil Kesehatan Kabupaten Sleman tahun 2016: Dinas Kesehatan Sleman; 2016

4. Murti, B. Desain dan Ukuran Sampel untuk Penelitian Kuantitatif dan Kualitatif di Bidang Kesehatan. Yogyakarta :Gadjah Mada University; 2011

5. Firmansyah, A., Chongviriyaphan, N., Dillon, D. H., Khan, N. C., Morita, T., Tontisirin, K., ... Vaughan, E. E. (2016). Fructans in the first 1000 days of life and beyond, and for pregnancy. Asia Pacific Journal of Clinical Nutrition, 25(4), 652-675.

https://doi.org/10.6133/apjcn.092016.02

6. Gladstone, M., Phuka, J., Mirdamadi, S., Chidzalo, K., Chitimbe, F., Koenraads, M., \& Maleta, K. (2018). The care, stimulation and nutrition of children from 0-2 in MalawiPerspectives from caregivers; \&quot;Who's holding the baby?\&quot; PloS One, 13(6), e0199757.

https://doi.org/10.1371/journal.pone.0199757

7. Kusrinah. Pendidikan Pra Lahir : Meningkatkan Kecerdasan Anak dengan bacaan Al-Qur"an. Fakultas Ilmu Tarbiyah dan Keguruan . IAIN Walisongo Semarang. SAWWA-Volume 8, Nomor 2, April 2013; 2013

8. Amalia, Taranindya Zulhi. "Promoting An Equality Gender In Prenatal Islamic Education". PALASTRèN: Vol. 4, No. 2, Desember 2011; 2011

9. Emoto, Masaru. Hikmah Air dalam Olah Jiwa, terj., Azam. Bandung: MQ Publishing; 2006

10. Gunes, F. E. Medical Nutrition Therapy for Hemodialysis Patients. http://dx.doi.org/10.5772/53473. [24 Agustus 2013]; 2013

11. Verduci, E., Martelli, A., Miniello, V.L., Landi, M., Mariani, B., Brambilla, M., Diaferio, L., Peroni, D.G., (2017). Nutrition in the first 1000 days and respiratory health: A descriptive review of the last five years' literature. Allergol. Immunopathol. (Madr.) 45, 405-413. https://doi.org/10.1016/j.aller.2017.01.003

12. Sharma, R., Gaffey, M.F., Alderman, H., Bassani, D.G., Bogard, K., Darmstadt, G.L., Das, J.K., de Graft-Johnson, J.E., Hamadani, J.D., Horton, S., Huicho, L., Hussein, J., Lye, S., Pérez-Escamilla, R., Proulx, K., Marfo, K., Mathews-Hanna, V., Mclean, M.S., Rahman, A., Silver, K.L., Singla, D.R., Webb, P., Bhutta, Z.A., n.d. (2018). Prioritizing research for integrated implementation of early childhood development and maternal, newborn, child and adolescent health and nutrition platforms. J. Glob. Health 7. https://doi.org/10.7189/jogh.07.011002

13. Edwards, R. C., Thullen, M. J., Henson, L. G., Lee, H., \& Hans, S. L. (2015). The association of breastfeeding initiation with sensitivity, cognitive stimulation, and efficacy among young mothers: a propensity score matching approach. Breastfeeding Medicine: The Official Journal of the Academy of Breastfeeding Medicine, 10(1), 13-9. https://doi.org/10.1089/bfm.2014.0123 
14. Khomsan A., dkk. Studi Tentang Pengetahuan Gizi Ibu dan Kebiasaan Makan pada rumah tangga di daerah dataran tinggi dan pantai. Jurnal Gizi dan Pangan. Vol 1, No 1: 23-28; 2013. 